\title{
Management Principles to Reduce the Risk of Residual Neuromuscular Blockade
}

\author{
Sorin J. Brull • Aaron F. Kopman • \\ Mohamed Naguib
}

Published online: 16 March 2013

(C) Springer Science + Business Media New York 2013

\begin{abstract}
The perioperative use of neuromuscular blocking agents has revolutionized medicine, and has allowed numerous and significant advances in the surgical management of patients. However, surgical advancement has not been devoid of attendant complications such as intraoperative patient recall, residual neuromuscular weakness, pulmonary aspiration of gastric contents, and need for tracheal reintubation. This chapter briefly reviews the various ways in which clinicians can optimize the timing and dosing of muscle relaxants, improve perioperative monitoring of muscle relaxation, and enhance the pharmacologic reversal of neuromuscular block. These strategies are intended to reduce the incidence of postoperative neuromuscular weakness and improve the safety of patients undergoing surgery and general anesthesia.
\end{abstract}

Keywords Neuromuscular block antagonism .

Neuromuscular blocking agents · Postoperative pulmonary complications - Residual neuromuscular blockade .

Residual paralysis

\section{S. J. Brull ( $\square)$}

Mayo Clinic College of Medicine, 4500 San Pablo Rd, Jacksonville, FL 32224, USA

e-mail: sjbrull@me.com

\author{
A. F. Kopman \\ Weill Cornell Medical College, 70 East 10th Street, \\ Apt. 17F, New York, NY 10003, USA \\ e-mail: akopman@nyc.rr.com \\ M. Naguib \\ Cleveland Clinic, Lerner College of Medicine of Case Western \\ Reserve University, 9500 Euclid Ave. NE6-306, \\ Cleveland, OH 44195, USA \\ e-mail: naguibm@ccf.org
}

\section{Introduction}

Neuromuscular blocking drugs are used primarily to facilitate tracheal intubation, decrease the potential for injury to vocal cords from laryngoscopy, and improve surgical conditions. However, neuromuscular blockers are not the sole determinant in achieving acceptable intubating conditions or preventing intraoperative movement of anesthetized patients. Guidelines are also needed regarding appropriate administration of anesthetic induction agents and titration of these agents intraoperatively to ensure an optimal plane of general anesthesia.

One of the integral aspects of anesthetic practice is achieving a smooth laryngoscopy and tracheal intubation without coughing, bucking, or any complications in an anesthetized patient. Intubating conditions depend on several factors, including the depth of anesthesia, the interval between drug administration and laryngoscopy, the dose of the hypnotic and neuromuscular blocking agents (NMBAs) administered, the anatomy of the airway, and the experience of the laryngoscopist. It cannot be overemphasized that maintenance of unconsciousness, analgesia and hemodynamic stability during induction of general anesthesia is a prerequisite for a safe tracheal intubation in the anesthetized patient. The following discussion is limited to routine (and not rapid sequence or difficult) intubating scenarios.

\section{Determinants of Tracheal Intubating Conditions}

The potency (in terms of the $\mathrm{mg} / \mathrm{kg}$ dose necessary to achieve a certain end-point) of nondepolarizing NMBAs is vastly variable. For this reason, equivalent doses of different drugs are expressed in terms of the dose required to achieve $95 \%$ of the intended effect - in this case, depression of the 
evoked neuromuscular response by $95 \%$. The dose required to achieve $95 \%$ neuromuscular block is $\mathrm{ED}_{95}$, and anesthesiologists have come to refer to a dose of $2 \times \mathrm{ED}_{95}$ as the "intubating dose." At this dose, adequate conditions for intubation will be achieved approximately $90-180 \mathrm{~s}$ after drug administration. This dose, it must be stressed, has never been accepted to be adequate for situations requiring a rapid sequence induction and intubation (RSII). Tracheal intubating conditions for non-emergent surgical anesthesia are related more closely to the degree of neuromuscular block of the laryngeal adductor muscles than to the degree of blockade typically monitored at the adductor pollicis muscle. In fact, onset of neuromuscular block is much more rapid in the muscles that are relevant to obtaining optimal intubating conditions (such as laryngeal adductors, diaphragm, and masseter muscles) than in the muscle typically monitored (adductor pollicis) [1,2]. These observations may seem contradictory because there is also convincing evidence that the effective plasma concentration of the drug necessary to achieve $50 \%$ of the intended effect $\left(\mathrm{EC}_{50}\right)$ for almost all drugs studied is between 50 and $100 \%$ higher at the diaphragm or larynx than it is at the adductor pollicis (i.e., the diaphragm and the larynx are more resistant to the effects of drugs than the muscles of the hand). Fisher et al. [3] explain this apparent contradiction by postulating more rapid equilibration (shorter mean equilibration half-life, $t_{1 / 2} k_{\mathrm{e} 0}$ ) between plasma and the effect compartment at these central muscles. This accelerated rate of equilibration probably represents little more than differences in regional blood flow. Therefore, muscle blood flow, rather than the drug's intrinsic potency, may be more important in determining the onset and depth of nondepolarizing neuromuscular block [4, 5]. More luxuriant blood flow (greater total blood flow per gram of muscle) at the diaphragm or larynx results in the central muscles receiving a higher peak plasma concentration of drug in the brief period before rapid redistribution is well under way.

Figure 1 illustrates that a less than complete block of short duration will result at the larynx or diaphragm when doses $<2.0 \times \mathrm{ED}_{95}$ are administered; furthermore, there is ample clinical evidence to show that rocuronium at doses of $1.5 \times \mathrm{ED}_{95}$ can reliably produce excellent conditions for intubation. Thus complete block at the larynx and/or diaphragm is not a necessary prerequisite for satisfactory tracheal intubation conditions. Kopman et al. [6] noted that $0.5 \mathrm{mg} / \mathrm{kg}$ rocuronium $\left(1.5 \times \mathrm{ED}_{95}\right.$ dose $)$ provided very satisfactory conditions for intubation (out of a total of 30 intubations, 25 were rated as excellent and 5 were rated as good) in patients anesthetized with $12.5 \mu \mathrm{g} / \mathrm{kg}$ alfentanil and $2.0 \mathrm{mg} / \mathrm{kg}$ propofol when laryngoscopy was delayed for $75 \mathrm{~s}$ following drug administration. The authors estimated that $1.5 \times \mathrm{ED}_{95}$ dose of rocuronium will produce a $95 \%$ block or greater in $98 \%$ of the population [6].
Tracheal intubation can also be achieved without the use of NMBAs. In 1992, Scheller et al. [7] demonstrated that an anesthetic induction consisting of at least $30 \mathrm{mcg} / \mathrm{kg}$ alfentanil and $2 \mathrm{mg} / \mathrm{kg}$ of propofol resulted in intubating conditions that were not different from those achieved with $4 \mathrm{mg} / \mathrm{kg}$ thiamylal and $1 \mathrm{mg} / \mathrm{kg}$ succinylcholine. Other investigators reported similar results using $4 \mathrm{mcg} / \mathrm{kg}$ remifentanil co-administered with either $2 \mathrm{mg} / \mathrm{kg}$ propofol in adults [8] or $3.5 \mathrm{mg} / \mathrm{kg}$ propofol in children [9]. However, the use of high doses of opioids is invariably associated with significant reductions in arterial blood pressure and heart rate [7-10]. When doses of $12.5 \mu \mathrm{g} / \mathrm{kg}$ alfentanil and $2 \mathrm{mg} / \mathrm{kg}$ propofol were administered, the frequency of excellent intubating conditions was $10 \%$; however, this increased to $83 \%$ with the addition of $2 \times \mathrm{ED}_{95}$ doses of neuromuscular blockers [6].

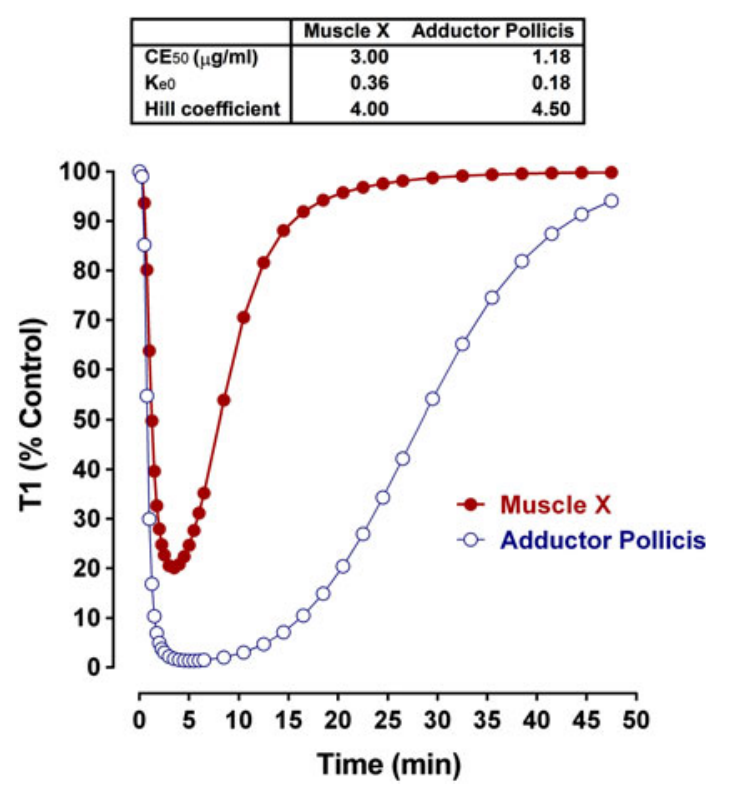

Fig. 1 A computer simulation based on Sheiner's model [24] and data reported by Wierda et al. [25]. The $\mathrm{ED}_{95}$ of rocuronium at the adductor pollicis muscle from this model is $0.33 \mathrm{mg} / \mathrm{kg}$. Rocuronium $0.45 \mathrm{mg} / \mathrm{kg}$ is given as a bolus at time zero. Muscle $\mathrm{X}$ represents a muscle (such as the diaphragm or the laryngeal adductors), which is less sensitive to the effects of nondepolarizing relaxants than the adductor pollicis muscle, but has greater blood flow. In this example the plasma concentration of rocuronium producing $50 \%$ block $\left(\mathrm{EC}_{50}\right)$ of muscle $\mathrm{X}$ is 2.5 times that of the adductor pollicis, but the half-life of equilibration between the plasma and effect compartment $\left(t_{1 / 2} k_{\mathrm{e} 0}\right)$ of muscle $\mathrm{X}$ is only half as long. The rapid equilibration between plasma concentrations of rocuronium and muscle $\mathrm{X}$ results in the more rapid onset blockade of muscle $\mathrm{X}$ than of the adductor pollicis. The greater $\mathrm{EC}_{50}$ at the $\mathrm{X}$ muscle explains the faster recovery of this muscle from neuromuscular block than the adductor pollicis. Lower blood concentrations of rocuronium must be achieved at the adductor pollicis, compared with muscle $\mathrm{X}$, before recovery begins. From Naguib M, Kopman AF, "Low dose rocuronium for tracheal intubation," Middle East J Anesthesiol 2003;17:193-204, [26] with permission from Middle East Journal of Anesthesiology and American University of Beirut Medical Center 
In addition, in a closed claims analysis, airway injuries were ranked the fourth most common anesthetic complication [11]. Of the 266 closed claims related to airway injury, 87 involved the larynx, and $80 \%$ of laryngeal injuries were associated with routine (non-difficult) laryngoscopies and tracheal intubations; only 17 of these cases were associated with difficult intubations [11]. Furthermore, with inadequate neuromuscular relaxation, motor reactions during tracheal intubation are more likely to result in laryngeal injury (e.g., arytenoid subluxation) [12]. Avoidance of neuromuscular blockers may also increase the risk of difficult tracheal intubation [13]. Therefore, it may be prudent and even desirable to administer at least a small dose of neuromuscular blockers to facilitate tracheal intubation $[14,15]$. Good to excellent conditions for intubation will be present $75-90 \mathrm{~s}$ after administration of rocuronium $0.45 \mathrm{mg} / \mathrm{kg}$ following induction of general anesthesia with alfentanil $15 \mu \mathrm{g} / \mathrm{kg}$ and propofol $2.0 \mathrm{mg} / \mathrm{kg}$.

It should be noted that monitoring the adductor pollicis muscle (thumb adduction) during onset of block is not a very useful indicator of the readiness for tracheal intubation, because paralysis of the adductor pollicis muscle lags behind onset of neuromuscular block at the laryngeal adductors, diaphragm, and masseter muscles $[2,16]$. In such instances, some consider it appropriate to gauge the readiness for tracheal intubation based on the time elapsed since NMBA administration, rather than be guided by objective monitoring of the adductor pollicis muscle response. As already mentioned above, the technique of administering a low-dose of NMBA is, of course, not suitable for the clinical setting of rapid sequence induction and intubation.

\section{Depth of Neuromuscular Block Required for Different Surgical Procedures}

After tracheal intubation, the extent (or "depth") of neuromuscular block should be determined by the surgical requirements. For instance, deep neuromuscular blockade with no response to train-of-four (TOF) stimulation may be necessary throughout ophthalmic, neurosurgical, thoracic, cardiac, and microsurgical procedures. A decrease in the tone of abdominal muscles during laparoscopic or robotic surgery also helps limit the increase in insufflation pressure of carbon dioxide $\left(\mathrm{CO}_{2}\right)$ during pneumoperitoneum, thereby decreasing intraabdominal pressure while providing optimal surgical conditions. In lower abdominal surgery, deep neuromuscular blockade is usually not needed to facilitate surgical exposure. In these situations, maintaining 1-2 twitches of TOF stimulation (a TOF count of 1-2) would be sufficient.

Residual neuromuscular weakness is common in the postanesthesia care unit secondary to nondepolarizing relaxants administered intraoperatively $[17,18 \cdot]$, and is a potentially serious patient safety issue $[19,20,21 \bullet]$. The use of a quantitative neuromuscular monitor (which measures and displays the TOF ratio in real time) is preferable to the use of a conventional nerve stimulator, because the clinician can make sure that the patient has recovered to a TOF ratio of $>0.9$. However, if a conventional nerve stimulator is used (without objective TOF monitoring), a reversal agent (i.e., anticholinesterases) should be administered at the end of surgery when four twitches are felt at the adductor pollicis muscle $[22,23 \cdot \bullet$. Even in the absence of subjective fade, a reduced dose of neostigmine $(0.025 \mathrm{mg} / \mathrm{kg})$ should be administered in the absence of objective monitoring.

\section{Does Intra-Operative Neuromuscular Monitoring Reduce the Incidence of Post-Operative Residual Neuromuscular Block?}

Although d-tubocurarine was introduced into clinical practice in 1942 [27], it was not until 1965 when editorial opinion suggested that intra-operative monitoring of neuromuscular function using a peripheral nerve stimulator should be standard practice [28]. That year, ChurchillDavidson argued that, "the only satisfactory method of determining the degree of neuromuscular block is to stimulate a motor nerve with an electric current and observe the contraction of the muscles innervated by that nerve" [28]. This statement implied that bedside clinical tests of neuromuscular recovery such as the 5-s head lift or adequacy of tidal volume were unreliable. This latter view has been rigorously substantiated [29, 30•]. A limitation of bedside tests is that they require an awake and cooperative patient. What the clinician requires, however, is a method of determining the extent of neuromuscular recovery prior to allowing the patient to emerge from anesthesia and prior to tracheal extubation. More recent editorial sentiment has gone much further: Eriksson suggested, “ $\ldots$ it is time to introduce objective neuromuscular monitoring [a device that can display the train-of-four ratio in real time] in all operating rooms. ... objective neuromuscular monitoring should be used whenever a nondepolarizing neuromuscular blocking agent is administered. Such monitoring is noninvasive, has little risk, and there are strong reasons to believe that its use can improve patient outcome" [31]. This editorial triggered a flurry of letters all asking the same question: "Where is the evidence?" [32-34].

The question, "can residual block have adverse clinical consequences?" is answered affirmatively in a separate review in the current issue of this journal [35]. The related concern, "does neuromuscular monitoring reduce the incidence of post-operative residual neuromuscular block (PORB)," is perhaps less easily answered. Common sense and expert opinion suggest that this should be so. 
Knowledge of the depth of neuromuscular block should allow the clinician to titrate NMBA administration more rationally and determine the need for antagonism more promptly and precisely. Nevertheless, a recent meta-analysis "could not demonstrate that the use of an intraoperative neuromuscular function monitor decreased the incidence of PORB" [17]. However, as the authors of manuscript noted, "... evidence based reviews are limited by the quality of the individual trials analyzed and reviewed. Nuances in protocol and apparently 'minor' variations in methodology may markedly affect outcome." Thus, "widely cited studies are often poorly designed to detect any advantages conferred by monitoring that might exist." Two such examples follow.

Pedersen et al. [36] conducted a randomized trial of 80 patients. In half, the degree of intraoperative blockade was assessed subjectively (by tactile evaluation) of the TOF response at the thumb. Clinicians were instructed to maintain the TOF count at one or two detectable responses, and antagonism of neuromuscular block with neostigmine was initiated at this depth of block. In the other half of the patients, the degree of block was evaluated solely by clinical criteria. In this group, reversal of residual paralysis was not attempted until spontaneous respiration or other indication of muscle activity was observed. The authors found that the use of a peripheral nerve stimulator (PNS) had no effect on the dose of relaxant given during anesthesia, or on the incidence of postoperative residual neuromuscular blockade. However, the authors' protocol almost guaranteed that results in the monitored group would be less than optimal. There is ample evidence that prompt and satisfactory anticholinesterase-induced antagonism at this level of block (TOF count of 1-2) is simply not a realistic goal $[37,38]$. Intraoperative neuromuscular monitoring should be used to help the clinician titrate doses of relaxant such that reversal with anticholinesterases can proceed more effectively-for instance, when the TOF count is 4 . In other words, if reversal is attempted at a relatively deep degree of block (as indicated by a TOF count of 1-2), the occurrence of residual weakness must be attributed to neostigmine's lack of effectiveness, not to the ineffectiveness of neuromuscular monitoring.

A non-randomized study by Fawcett et al. [39] emphasizes this point. A total of 150 patients were given atracurium or vecuronium intravenously either by intermittent bolus or continuous infusion. No attempt was made to influence the conduct of anesthesia, the choice of NMBAs, or whether to monitor the neuromuscular function. Peripheral nerve stimulators were used intraoperatively in sixty percent of the cases. The incidence of PORB (a TOF ratio $<0.70$ ) on arrival in the recovery room, as measured by EMG, was not decreased in patients in whom a PNS device was used. The study unfortunately gives the reader no insight into how clinical decisions were made. If monitored patients were routinely kept at a deep level of neuromuscular block (e.g., at a TOF count of two or fewer detectable responses), then one may argue that a PNS might be counterproductive in some circumstances. Relaxants might have been administered by clinicians in response to a perceived need to attain a specific depth of block (TOF count $<2$ ) at the thumb, rather than on the basis of the clinical requirements of the moment.

Studies that support the use of PNS units [40-45, 46••], however, can be equally unconvincing. They all show a reduced incidence of PORB when PNS units are employed, but the dose of NMBA administered is usually the same in both monitored and non-monitored patient groups. Why, then, is there a lower incidence of PORB in the monitored patients? Despite considerable speculation, a truly persuasive explanation for these observations is, we think, still lacking. Perhaps not unexpectedly, the most convincing evidence comes from studies that have investigated the effectiveness of objective monitoring techniques on outcome-not merely subjective assessment. Proof that the use of objective neuromuscular monitors can decrease the incidence of PORB comes from two studies by Baillard et al. [47, 48]. The first, conducted in 1995, was a prospective study of the incidence of PORB following vecuronium administration in 568 consecutive patients over a 3-month period. No anticholinesterase antagonists were used in this series of patients, as was customary in the authors' department, and PNS devices were rarely used intra-operatively. Upon patient arrival in the PACU, postoperative residual block was found in $42 \%$ of patients (as defined by an acceleromyographic TOF ratio of $<0.70$ ). In response to these disturbing statistics, Baillard's department equipped all of their operating rooms with acceleromyographic (objective) monitors for intraoperative use. In addition, the results of their findings regarding the incidence of PORB were distributed to their staff, and they instituted an education program that recommended acceleromyographic monitoring of neuromuscular function and stressed the indications for neostigmine reversal of residual block. These efforts were repeated at three-month intervals. In the decade between these studies, the use of intraoperative monitoring of neuromuscular function rose from 2 to $60 \%$, and reversal of neuromuscular block increased from 6 to $42 \%$ of cases. As a result of these changes in clinical practice, the incidence of PORB (acceleromyographic TOF ratio of $<0.90)$ in Baillard's department decreased from 62 to $<4 \%$ ! The authors' conclude that their study "confirms the positive impact of neuromuscular monitoring and reversal of neuromuscular block in routine anaesthetic practice" [48]. 


\section{The Efficacy and Limitations of Neostigmine as a Reversal Agent: Implications for the Timing of Drug Administration and Tracheal Extubation}

At the time this chapter was written (the fall of 2012) the anticholinesterases edrophonium, pyridostigmine and neostigmine were the only drugs available in North America for the antagonism of nondepolarizing agent-induced neuromuscular block, with neostigmine being by far the most commonly administered agent. Even in Asia and Europe, where sugammadex is available, economic considerations limit its use. Thus neostigmine, at least for the moment, remains the primary antagonist of nondepolarizing block in the anesthesiologist's armamentarium. It is therefore important to understand the drug's efficacy and limitations in this role.

Nondepolarizing neuromuscular block is competitive in nature. Molecules of acetylcholine (ACh) and neuromuscular blocking drugs (each of which having a receptor occupancy time measured in msec) are competing for access to nicotinic receptors at the myoneural junction. If the concentration of NMBA is sufficiently high, it "wins" this competition, binds to the nicotinic receptor, and renders it inactive, resulting in muscle paralysis. If the enzymatic destruction of ACh is slowed by the administration of an acetylcholinesterase, the concentration of $\mathrm{ACh}$ at the neuromuscular junction increases, shifting the concentration balance in favor of the neurotransmitter (i.e., ACh), and recovery phase commences. However, once acetylcholinesterase is maximally inhibited, additional doses of neostigmine will have no further effect. In fact, additional neostigmine at this time could produce an opposite effect, resulting in muscle weakness. Thus, there is a ceiling to the concentration of ACh that can be reached at the neuromuscular junction. However, there is no limit to the concentration of nondepolarizing agent that can be achieved at the neuromuscular junction if the clinician administers very large doses in an attempt to reach a deep level of block or speed up the onset of block. To quote Beemer, "anticholinesterases have a 'ceiling' to the extent of the block which can be completely antagonized. When reversal of NM block greater than this ceiling $(\mathrm{T} 1<30 \%)$ is attempted, the peak effect of the antagonist is followed by a slow plateau phase which represents the balance between diminishing anticholinesterase activity and spontaneous recovery of neuromuscular block" [49]. "In practical terms, the maximum depth of block that can be antagonized approximately corresponds to the reappearance of the fourth response to TOF stimulation" [50]. It should be noted, however, that these comments were made in an era when a TOF ratio of 0.70 at the adductor pollicis muscle was considered to represent satisfactory clinical recovery. More recent evidence agrees that, "To achieve rapid (within $10 \mathrm{~min}$ ) reversal to a TOF ratio of 0.70 in more than $87 \%$ of patients, three or four tactile responses should be present at the time of neostigmine administration." However, "It was not possible within $30 \mathrm{~min}$ to achieve a TOF ratio of 0.9 in all patients, regardless of the number of tactile responses present at neostigmine administration" [38].

Thus, it is incorrect to assume that as long as some evoked response to TOF stimulation is present, acceptable reversal is promptly achievable. Visual or tactile estimation of the extent of recovery can be very misleading, since once the TOF ratio exceeds 0.40 , the ability to subjectively detect the presence of any fade becomes highly unreliable [51]. The potential discrepancy between an anesthesiologist's clinical impression and objective reality was nicely illustrated in the following study [52]. The authors kept the TOF count at one (as determined by EMG monitoring) with an intravenous (iv) infusion of either rocuronium or cisatracurium ( $N=20$ patients in each group) for an average of $2.5 \mathrm{~h}$. At the end of surgery the infusion was turned off and iv neostigmine $0.05 \mathrm{mg} / \mathrm{kg}$ was administered. Twenty minutes later, the average TOF ratio was 0.81 ; however, the standard deviation was 0.12 ! Five of the 40 patients had TOF ratios $<0.70$ but $>0.40$. Thus, $13 \%$ of the authors' patients had grossly inadequate return of neuromuscular function $20 \mathrm{~min}$ after antagonism, which would go undetected by the anesthesiologist who uses subjective assessment! Reversal at a TOF count of 2 (assessed tactilely) results in somewhat better results; the average TOF ratio $15 \mathrm{~min}$ after neostigmine antagonism is $0.83 \pm 0.08$, but $12 \%$ of subjects still fail to reach a TOF ratio of 0.90 within $30 \mathrm{~min}$ [37].

These observations have practical clinical implications. First, every effort should be made to assure that the tactile or visual TOF count at the hand has spontaneously recovered to a value of 4 (ideally with minimum fade assessed subjectively) prior to neostigmine administration. This level of recovery is best achieved by titrating incremental doses of NMBA to meet surgical conditions, not to some arbitrary TOF count or time interval. The TOF count as determined by facial nerve stimulation (whether at the orbicularis oculi or supercilii muscles) consistently overestimates recovery at the hand muscles, and gives the clinician a false sense of security; this practice is to be discouraged [53, 54]. In fact, very recent data documented that qualitative (subjective) assessment of TOF monitoring performed at the eye muscles resulted in a fivefold increase in the risk of postoperative residual block compared with assessment at the adductor pollicis muscle [23]. Second, if satisfactory neuromuscular recovery (a TOF ratio $\geq 0.90$ ) is to be achieved at the time of tracheal extubation, neostigmine administration should precede this maneuver by not less than $10 \mathrm{~min}$, since the drug's peak effect may not manifest itself until approximately this interval has elapsed [55]. 
Unfortunately, spontaneous return to a TOF count of four frequently has not yet taken place as the last surgical stitch is being placed. How then should a clinician proceed when the TOF count is only 1, 2 or 3 at the end of surgery? The authors envision two approaches to such a scenario. If an objective neuromuscular monitor (EMG, KMG or AMG) is available, neostigmine can be administered without waiting for further recovery. This is done with the expectation that it will probably be at least $20 \mathrm{~min}$ (and likely longer) before a TOF ratio of 0.90 is achieved and tracheal extubation can be safely accomplished. The advantage of this approach is that occasionally, more rapid return of neuromuscular function is observed and anesthesia can be terminated earlier with confidence that post-operative residual block will not be a problem. In the absence of quantitative monitoring, the only safe strategy is to wait until the TOF count has returned to four detectable responses before attempting reversal with anticholinesterases. Thus, occasionally it may be necessary (as inconvenient as it may be) to remind the operating room staff that the surgery may be over, but the case is not finished until the patient's trachea can be extubated safely.

\section{Limitations of Current Pharmacologic Antagonists and the Promise of Future Agents}

In previous sections of this review, reference has been made to the limited effectiveness of anticholinesterases in reversing moderate and deep degrees of block (i.e., when the TOF count is 3 or fewer responses). This "ceiling" effect has several important clinical implications: first, it is clear that neostigmine will be ineffective at reversing deep block. However, interestingly, neostigmine may also induce neuromuscular weakness during near-complete spontaneous recovery [56]. The mechanism for this muscular weakness induced by neostigmine is impairment of normal function of the genioglossus and diaphragm muscles, resulting in a decrease in the volume of the upper airway [57, 58]. In contrast, some of newer reversal agents may solve many, if not all, of the limitations of current anticholinesterases.

Sugammadex, which is not currently available in the United States, has been used in clinical settings since 2008, and is now approved in 72 countries world-wide. Application for review by the US Food and Drug Administration (FDA) has recently been approved, and a decision regarding approval for clinical use in the US is expected by mid-summer 2013. Sugammadex is a modified gamma-cyclodextrin that forms very tight complexes with aminosteroid NMBAs, particularly rocuronium and vecuronium. The complexation is nearly irreversible, and results in a decrease in the plasma levels of free (unbound) sugammadex molecules, which results in diffusion of free drug away from the neuromuscular junction. The inactive sugammadex-rocuronium complex is excreted almost entirely in the urine. The dosing recommendations are based on the depth of neuromuscular block it is intended to antagonize: a $2 \mathrm{mg} / \mathrm{kg}$ dose is recommended for reversal of shallow block (TOF count of 1-2); a dose of $4 \mathrm{mg} / \mathrm{kg}$ is recommended for reversal of deep block (PTC count of 1-2); and a dose of $16 \mathrm{mg} / \mathrm{kg}$ is recommended for rapid reversal of rocuronium-induced block almost immediately after NMBA administration. The reversal of neuromuscular block occurs within $3 \mathrm{~min}$ from any depth of block $[59,60]$. In fact, the total time from administration of high-dose $(1.2 \mathrm{mg} / \mathrm{kg})$ rocuronium until sugammadex-induced $(16 \mathrm{mg} / \mathrm{kg}$ ) recovery of TOF ratio to $>0.90$ was shorter than the spontaneous recovery noted after $1 \mathrm{mg} / \mathrm{kg}$ succinylcholine [61]. Sugammadex is not metabolized and it is excreted unchanged by the kidneys. It is inert and does not bind to nicotinic receptors. Common side effects are similar to placebo, and initial concerns about hypersensitivity have not been borne out by the experience with over 3 million administered doses. The effects of sugammadex on coagulation are very small, and dissipate within an hour. Binding of sugammadex to oral contraceptives has the equivalent effect of missing one dose.

For more than 50 years, the sole antagonists of nondepolarizing neuromuscular agents were anticholinesterases. The mechanism of action of sugammadex-formation of stable complexes with steroidal NMBAs-may point the way to the future development of reversal agents without the current efficacy limitations and significant side effects of anticholinesterases [62].

\section{Conclusions}

With all the information currently available, some of which appears to be contradictory, what are clinicians to do in order to ensure the safety and comfort of their patients? On the one hand, recent data [63••] continue to document that the use of intermediate-acting NMBAs increases the incidence of perioperative pulmonary complications. In fact, the perioperative use of NMBAs was associated with a $36 \%$ increased incidence of significant oxygen desaturation ( $\mathrm{SpO} 2<90 \%$ ) following tracheal extubation, and a $40 \%$ increase in the rates of tracheal reintubation that required unplanned admission to the intensive care unit. Such studies suggest that we need better, timelier and more carefully administered anticholinesterase reversal. On the other hand, the very administration of neostigmine at the time when the neuromuscular function is nearly recovered may itself induce neuromuscular weakness! The apparent conflict can, in fact, be explained by the fact that at deep block, the effectiveness of neostigmine reaches a plateau, and residual block is likely; at the other end of the recovery curve, when the recovery is almost complete and ACh does not face much 
competition for the postsynaptic receptors from NMBA molecules, the additional $\mathrm{ACh}$ at the junction may itself induce block. From the foregoing, it appears that the rational approach would be for the clinician to determine, by objective monitoring, exactly where along the recovery curve the patient is at the time of intended reversal. As described above, this will have important clinical implications on whether, when, and how much, reversal agent the patient should receive.

Disclosure Sorin J. Brull has received compensation from Merck for serving both as a consultant and as an Advisory Board member, and has served as an unpaid Executive Committee Member for the Anesthesia Patient Safety Foundation (APSF). Aaron F. Kopman and Mohamed Naguib declare that the authors have no conflict of interest.

\section{References}

Papers of particular interest, published recently, have been highlighted as:

- Of importance

- Of major importance

1. Meistelman C, Plaud B, Donati F. Rocuronium (ORG 9426) neuromuscular blockade at the adductor muscles of the larynx and adductor pollicis in humans. Can J Anaesth. 1992;39:665-9.

2. Cantineau JP, Porte F, d'Honneur G, Duvaldestin P. Neuromuscular effects of rocuronium on the diaphragm and adductor pollicis muscles in anesthetized patients. Anesthesiology. 1994;81: 585-90.

3. Fisher DM, Szenohradszky J, Wright PM, Lau M, Brown R, Sharma M. Pharmacodynamic modeling of vecuronium-induced twitch depression. Rapid plasma-effect site equilibration explains faster onset at resistant laryngeal muscles than at the adductor pollicis. Anesthesiology. 1997;86:558-66.

4. Goat VA, Yeung ML, Blakeney C, Feldman SA. The effect of blood flow upon the activity of gallamine triethiodide. $\mathrm{Br} \mathrm{J}$ Anaesth. 1976;48:69-73.

5. De Haes A, Houwertjes MC, Proost JH, Wierda JM. An isolated, antegrade, perfused, peroneal nerve anterior tibialis muscle model in the rat: a novel model developed to study the factors governing the time course of action of neuromuscular blocking agents. Anesthesiology. 2002;96:963-70.

6. Kopman AF, Klewicka MM, Neuman GG. Reexamined: the recommended endotracheal intubating dose for nondepolarizing neuromuscular blockers of rapid onset. Anesth Analg. 2001;93: 954-9.

7. Scheller MS, Zornow MH, Saidman LJ. Tracheal intubation without the use of muscle relaxants: a technique using propofol and varying doses of alfentanil. Anesth Analg. 1992;75:788-93.

8. Stevens JB, Wheatley L. Tracheal intubation in ambulatory surgery patients: using remifentanil and propofol without muscle relaxants. Anesth Analg. 1998;86:45-9.

9. Klemola UM, Hiller A. Tracheal intubation after induction of anesthesia in children with propofol-remifentanil or propofolrocuronium. Can J Anaesth. 2000;47:854-9.

10. Jabbour-Khoury SI, Dabbous AS, Rizk LB, Abou Jalad NM, Bartelmaos TE, El-Khatib MF, Baraka AS. A combination of alfentanil-lidocaine-propofol provides better intubating conditions than fentanyl-lidocaine-propofol in the absence of muscle relaxants: [La combinaison d'alfentanil-lidocaine-propofol fournit de meilleures conditions d'intubation que celle de fentanyl-lidocainepropofol en l'absence de myorelaxants]. Can J Anaesth. 2003;50: 116-20.

11. Domino KB, Posner KL, Caplan RA, Cheney FW. Awareness during anesthesia: a closed claims analysis. Anesthesiology. 1999;90:1053-61.

12. Paulsen FP, Rudert HH, Tillmann BN. New insights into the pathomechanism of postintubation arytenoid subluxation. Anesthesiology. 1999;91:659-66.

13. Lundstrom LH, Moller AM, Rosenstock C, Astrup G, Gatke MR, Wetterslev J. Avoidance of neuromuscular blocking agents may increase the risk of difficult tracheal intubation: a cohort study of 103,812 consecutive adult patients recorded in the Danish anaesthesia database. Br J Anaesth. 2009;103:283-90.

14. Hovorka J, Honkavaara P, Korttila K. Tracheal intubation after induction of anaesthesia with thiopentone or propofol without muscle relaxants. Acta Anaesthesiol Scand. 1991;35:326-8.

15. Naguib M, Samarkandi A, Riad W, Alharby SW. Optimal dose of succinylcholine revisited. Anesthesiology. 2003;99:1045-9.

16. Wright PM, Caldwell JE, Miller RD. Onset and duration of rocuronium and succinylcholine at the adductor pollicis and laryngeal adductor muscles in anesthetized humans. Anesthesiology. 1994; $81: 1110-5$.

17. Naguib M, Kopman AF, Ensor JE. Neuromuscular monitoring and postoperative residual curarisation: a meta-analysis. $\mathrm{Br} \mathbf{J}$ Anaesth. 2007;98:302-16.

18. • Naguib M, Kopman AF, Lien CA, Hunter JM, Lopez A, Brull SJ: A survey of current management of neuromuscular block in the United States and Europe. Anesth Analg 2010; 111: 110-9. A survey that documents most US and European anesthesiologists estimate the incidence of residual neuromuscular weakness to be $<1 \%$. The reported availability of quantitative monitors is almost 4 times greater in Europe than in the United States. The authors suggest consideration be given to improved education and development of guidelines or best practices.

19. Brull SJ, Naguib M, Miller RD. Residual neuromuscular block: rediscovering the obvious. Anesth Analg. 2008;107:11-4.

20. Murphy GS, Szokol JW, Marymont JH, Greenberg SB, Avram MJ, Vender JS. Residual neuromuscular blockade and critical respiratory events in the postanesthesia care unit. Anesth Analg. 2008;107:130-7.

21. - Brull SJ, Murphy GS: Residual neuromuscular block: lessons unlearned. Part II: Methods to reduce the risk of residual weakness. Anesth Analg 2010;111:129-140. Comprehensive review of various neuromuscular management strategies aimed at reducing the risk of residual paralysis in the early postoperative period.

22. Kopman AF, Eikermann M. Antagonism of non-depolarising neuromuscular block: current practice. Anaesthesia. 2009;64(Suppl 1): $22-30$.

23. •• Thilen SR, Hansen BE, Ramaiah R, Kent CD, Treggiari MM, Bhananker SM: Intraoperative neuromuscular monitoring site and residual paralysis. Anesthesiology 2012;117:964-72. Excellent study that demonstrates the current practice of subjective monitoring of facial muscle evoked responses results in 5-fold overestimation of neuromuscular recovery.

24. Sheiner LB, Stanski DR, Vozeh S, Miller RD, Ham J. Simultaneous modeling of pharmacokinetics and pharmacodynamics: application to d-tubocurarine. Clin Pharmacol Ther. 1979;25: 358-71.

25. Wierda JM, Kleef UW, Lambalk LM, Kloppenburg WD, Agoston S. The pharmacodynamics and pharmacokinetics of Org 9426, a new non-depolarizing neuromuscular blocking agent, in patients anaesthetized with nitrous oxide, halothane and fentanyl. Can J Anaesth. 1991;38:430-5. 
26. Naguib M, Kopman AF. Low dose rocuronium for tracheal intubation. Middle East J Anesthesiol. 2003;17:193-204.

27. Griffith HR, Johnson GE. The use of curare in general anesthesia. Anesthesiology. 1942;3:412-20.

28. Churchill-Davidson HC. The d-Tubocurarine dilemma. Anesthesiology. 1965;26:132-3.

29. Beemer GH, Rozental P. Postoperative neuromuscular function. Anaesth Intens. Care. 1986;14:41-5.

30. • Heier T, Caldwell JE, Feiner JR, John R, Liu L, Ward T, Wright PM. Relationship between normalized adductor pollicis train-offour ratio and manifestations of residual neuromuscular block: a study using acceleromyography during near steady-state concentrations of mivacurium. Anesthesiology 2010;113:825-32. Excellent study that found volunteers' lung vital capacity decreased linearly with decreasing TOF ratio. Equally importantly, this study documents that when recovery is complete (TOF ratio $>0.90$ ), none of the volunteers experienced clinical effects of residual block.

31. Eriksson LI. Evidence-based practice and neuromuscular monitoring: it's time for routine quantitative assessment. Anesthesiology. 2003;98:1037-9.

32. Kempen PM. Obligate acceleromyography and pharmacologic reversal of all neuromuscular blocking agents: really, and where is the clinical outcome? Anesthesiology. 2004;100:453.

33. Pinsker MC. Evidence-based practice and neuromuscular monitoring. Anesthesiology. 2004;100:453-4.

34. Rizzi RR. Neuromuscular monitoring advancement. Anesthesiology. 2004;100:454.

35. Kopman AF, Brull SJ. Is post-operative residual neuromuscular block associated with adverse clinical outcomes? What is the evidence? Current Anesthesiology Reports. 2013;1.

36. Pedersen T, Viby-Mogensen J, Bang U, Olsen NV, Jensen E, Engbæk J. Does perioperative tactile evaluation of the train-offour response influence the frequency of postoperative residual neuromuscular blockade? Anesthesiology. 1990;73:835-9.

37. Kopman AF, Zank LM, Ng J, Neuman GG. Antagonism of cisatracurium and rocuronium block at a tactile train-of-four count of 2: should quantitative assessment of neuromuscular function be mandatory? Anesth Analg. 2004;98:102-6.

38. Kirkegaard H, Heier T, Caldwell JE. Efficacy of tactile-guided reversal from cisatracurium-induced neuromuscular block. Anesthesiology. 2002;96:45-50.

39. Fawcett WJ, Dash A, Francis GA, Liban JB, Cashan JN. Recovery from neuromuscular blockade: residual curarisation following atracurium or vecuronium by bolus dosing or infusions. Acta Anaesthiol Scand. 1995;39:288-93.

40. Shorten GD, Merk H. Perioperative train-of-four monitoring and residual curarization. Can J Anaesth. 1995;42:711-5.

41. Fruergaard K, Viby-Mogensen J, Berg H. el-Mahdy AM. Tactile evaluation of the response to double burst stimulation decreases, but does not eliminate, the problem of postoperative residual paralysis. Acta Anaesthesiol Scand. 1998;42:1168-74.

42. Ueda N, Muteki T, Tsuda H, Inoue S, Nishina H. Is the diagnosis of significant residual neuromuscular blockade improved by using double burst nerve stimulation? Eur J Anaesthiol. 1991;8: 213-8.

43. Mortensen CR, Berg H, El-Mahdy A, Viby-Mogensen J. Perioperative monitoring of neuromuscular transmission using acceleromyography prevents residual neuromuscular block following pancuronium. Acta Anaesthiol Scand. 1995;39:797-801.

44. Gatke MR, et al. Postoperative muscle paralysis after rocuronium: less residual block when acceleromyography is used. Acta Anaesthesiol Scand. 2002;46:207-13.

45. Murphy GS, Szokol JW, Marymount JH, Greenberg SB, Avram MJ, Vender JS, Nisman M. Intraoperative acceleromyography monitoring reduces the risk of residual neuromuscular blockade and adverse respiratory events in the postanesthesia care unit. Anesthesiology. 2008;109:389-98.

46. • Murphy, GS, Szokol JW, Avram, MJ, Greenberg SB, Marymont JH, Vender JS, Gray, J, Landry E, Gupta DK. Intraoperative acceleromyography monitoring reduces symptoms of muscle weakness and improves quality of recovery in the early postoperative period. Anesthesiology 2011;115:946-54. Important study that demonstrated patients who were monitored objectively (acceleromyography) were less likely to have residual weakness postoperatively than patients undergoing routine (subjective) assessment; more importantly, the authors showed that patients' symptoms of weakness were reduced when objective monitoring was used, thereby improving the quality of recovery.

47. Baillard C, Gehan G, Reboul-Marty J, Larmignat P, Samama CM, Cupa M. Residual curarization in the recovery room after vecuronium. Br J Anaesth. 2000;84:394-5.

48. Baillard C, Clec'h C, Catineau J, Salhi F, Gehan G, Cupa M, Samara CM. Postoperative residual neuromuscular block: a survey of management. Br J Anaesth. 2005;95:622-6.

49. Beemer GH, Bjorksten AR, Dawson PJ, Dawson RJ, Heenan PJ, Robertson BA. Determinants of the reversal time of competitive neuromuscular block by anticholinesterases. Br J Anaesth. 1991; 66:469-75

50. Beemer GH, Goonetilleke PH, Bjorksten AR. The maximum depth of an atracurium neuromuscular block antagonized by edrophonium to effect adequate recovery. Anesthesiology. 1995; 82:852-8.

51. Viby-Mogensen J, Jensen NH, Engbaek J, Ording H, Skovgaard LT, Chraemmer-Jorgensen B. Tactile and visual evaluation of the response to train-of-four nerve stimulation. Anesthesiology. 1985;63:440-3.

52. Kopman AF, Kopman DJ, Ng J, Zank LM. Antagonism of profound cisatracurium and rocuronium block: the role of objective assessment of neuromuscular function. J Clin Anesth. 2005;17: $30-5$.

53. Caffrey RR, Warren ML, Becker KE. Neuromuscular blockade monitoring comparing the orbicularis oculi and adductor pollicis muscles. Anesthesiology. 1986;65:95-7.

54. Larsen PB, Gatke MR, Fredensborg BB, Berg H, Engbaek J, Viby-Mogensen J. Acceleromyography of the orbicularis oculi muscle II: comparing the orbicularis oculi and adductor pollicis muscles. Acta Anaesthesiol Scand. 2002;46:1131-6.

55. Kirkegaard-Nielsen H, Helbo-Hansen HS, Lindholm P, Severinsen IK, Bülow K. Time to peak effect of neostigmine at antagonism of atracurium- or vecuronium-induced neuromuscular block. J Clin Anesth. 1995;7:635-9.

56. Caldwel JE. Reversal of residual neuromuscular block with neostigmine at one to four hours after a single intubating dose of vecuronium. Anesth Analg. 1995;80:1168-74.

57. Eikermann M, Fassbender P, Malhotra A, Takahashi M, Kubo S, Jordan AS, Gautam S, White DP, Chamberlin NL. Unwarranted administration of acetylcholinesterase inhibitors can impair genioglossus and diaphragm muscle function. Anesthesiology. 2007:107:621-9.

58. Eikermann M, Zaremba S, Malhotra A, Jordan AS, Rosow C, Chamberlin NL. Neostigmine but not sugammadex impairs upper airway dilator muscle activity and breathing. $\mathrm{Br} \mathrm{J}$ Anaesth. 2008;101:344-9.

59. Shields M, Giovannelli M, Mirakhur RK, et al. Org 25969 (sugammadex), a selective relaxant binding agent for antagonism of prolonged rocuronium-induced neuromuscular block. Br J Anaesth. 2006;961:36-43.

60. Sorgenfrei IF, Norrild K, Larsen PB, et al. Reversal of rocuronium-induced neuromuscular block by the selective relaxant binding agent sugammadex: a dose-finding and safety study. Anesthesiology. 2006;1044:667-74. 
61. Naguib M. Sugammadex: another milestone in clinical neuromuscular pharmacology. Anesth Analg. 2007;1043:575-81.

62. Grosse-Sundrup M, Hoffmann U, Elamine L, Ma D, Zhang B, Eikerman-Haerter K, Ayata C, Isaacs L, Eikermann M. New broad spectrum reversal agent for benzylisoquinoline and steroidal neuromuscular blocking agents. Anesthesiology 2013; A003 (abstract).

63. • Grosse-Sundrup M, Henneman JP, Sandberg WS, Bateman BT, Uribe JV, Nguyen NT, Ehrenfeld JM, Martinez EA, Kurth T,
Eikermann M. Intermediate acting non-depolarizing neuromuscular blocking agents and risk of postoperative respiratory complications: prospective propensity score matched cohort study. BMJ 2012 Oct 15:345:e6329. Controversial, but well conducted propensity score matched study that proves an association between the use of NMBAs (and neostigmine) and an increased risk of significant oxygen desaturation, need for tracheal reintubation with intensive care unit admission, and respiratory complications. 